\title{
Gill net selectivity for European hake Merluccius merluccius from southern Portugal: implications for fishery management
}

\author{
Miguel Neves dos SANTOS, ${ }^{1 *}$ Miguel GASPAR, ${ }^{1}$ Carlos Costa MONTEIRO ${ }^{1}$ AND \\ KARIM ERZINI ${ }^{2}$ \\ ${ }^{1}$ Instituto de Investigação das Pescas e do Mar, Centro Regional de Investigação Pesqueira do Sul, \\ P-8700-305 Olhão and ${ }^{2}$ Centro de Ciências do Mar, Universidade do Algarve, Faculdade de Ciências \\ do Mar e do Ambiente, Campus de Gambelas, P-8000-117 Faro, Portugal
}

\begin{abstract}
A study of European hake Merluccius merluccius gill net selectivity was undertaken off the Algarve (Southern Portugal), between 1999 and 2001. Four nominal mesh sizes (70, 80, 90 and $100 \mathrm{~mm}$ ) were used in fishing trials and the 'share each length class catch total' (SELECT) method was used to fit gill net selectivity curves. Hake were caught in the same size range by all mesh sizes, between 17 and $65 \mathrm{~cm}$ total length. While most fishes were wedged, significant and similar proportions were entangled in all mesh sizes, contributing to the wide size range, and in some cases, bimodal shape of catch size frequency distributions. Insignificant numbers of undersized hake were caught, with most catches consisting of mature female fish. Catch rates decreased sharply with increasing mesh size. The bimodal model gave the best fit for hake that were wedged, with estimated modal lengths of $40.1,46.7$ and $51.0 \mathrm{~cm}$ for the 70,80 and $90 \mathrm{~mm}$ nominal mesh sizes, respectively. The high catch per unit effort of the smallest mesh size, with most fish caught being female, together with the fact that the modal length of the fitted selectivity curve is well below the size at maturity for hake in Portuguese waters, suggests that the $80 \mathrm{~mm}$ nominal mesh size is more appropriate for ensuring resource sustainability.
\end{abstract}

KEYWORDS: European hake, fishery management, gill net, Merluccius merluccius, selectivity.

\section{INTRODUCTION}

The European hake Merluccius merluccius is widely distributed in the north-eastern Atlantic, Mediterranean and Black Sea. ${ }^{1}$ It is most common at depths of $100-300 \mathrm{~m}$ but its bathymetric range extends from shallow waters to approximately $1000 \mathrm{~m}$ depth. ${ }^{2,3}$ It is one of the most important commercial demersal species in Europe ${ }^{4-6}$ and the major demersal resource in the Iberian region, ${ }^{7}$ being characterized by high market prices.

For fisheries management purposes there are two stocks, the northern and the southern (International Council for the Exploration of the Seas (ICES) divisions VIIIc and IXa), with a border in the Bay of Biscay. Since the early 1980s when landings peaked at 23000 ton in 1983, there has been a steady decline to less than 8000 ton per year in

${ }^{*}$ Corresponding author: Tel: 351-289-700-504.

Fax: 351-289-700-535. Email: mnsantos@ipimar.ualg.pt

Received 7 May 2002. Accepted 4 March 2003. recent years. The trend in landings has been accompanied by decreases in the spawning stock biomass and in recruitment, despite the fact that there has been a general decrease in fishing effort over the past decade.

The management of the hake southern stock is by total allowable catch (TAC) and other technical measures, namely a minimum landing size of $27 \mathrm{~cm}$ total length (TL), closed areas to protect juveniles and minimum mesh sizes that depend on areas and gears. Hake are caught in multispecies fisheries involving a variety of different gear such as trawls, long-line, trammel nets and gill nets.

Gill net fisheries targeting hake exist in a number of European countries, such as Portugal, Spain, France, England, Italy and Greece..$^{8-14}$ Off the Algarve coast (southern Portugal, ICES subarea IXa) this fishery assumes particular economic relevance, representing $26 \%$ of the total landings of this species in Portugal. ${ }^{15}$

Because of the selective nature of gill nets, mesh size can be controlled to restrict the size of fish 
captured, and either selection or retention curves can be used to calculate an optimal mesh size. Furthermore, managers would like to predict what effect any proposed change in mesh regulations might have on the size composition of the catch. For these reasons, gill net selectivity has often been estimated using a variety of methods for different fish species (e.g. reviews) ${ }^{16,17}$ In recent years, new methods have been developed. ${ }^{18-20}$ To the authors' best knowledge, very little work been done on hake gill net selectivity. ${ }^{10,21,22}$ The objective of the present paper was to study gill net selectivity for hake and to evaluate the implications of an increase in minimum legal mesh size of $60 \mathrm{~mm}$ for the Algarve coast (southern Portugal) fishery.

\section{MATERIALS AND METHODS}

\section{Nets}

Hake commercial fishermen were interviewed in order to obtain details on the design and operation of the nets used in the deep-water hake fishery off the Algarve coast and a representative design was then chosen. The differences found mainly concerned the mesh size and height of the nets, as a result of the depth of the fishing ground, with smaller mesh sizes being used in shallower waters. The technical specifications of the experimental gill nets are presented in Table 1. All specifications correspond to the commercial practice except for the $100 \mathrm{~mm}$ mesh size, which is not used in the commercial fishery. Inside mesh size was measured between opposite knots when fully stretched, taking a sample of 25 randomly chosen meshes, using a steel ruler and light manual force to stretch the mesh. All nets were made of a polyamide monofilament light green twine with a diameter of $0.3 \mathrm{~mm}$. Floatation was given by 25 polyvinyl chloride (PVC) floats (93 gf) in each panel. These were approximately $50 \mathrm{~m}$ long and $6.3 \mathrm{~m}$ high. The hanging ratio of these nets was 0.50 on the float rope and 0.52 on the lead rope. The experimental fleet consisted of 15 randomly distributed panels of each mesh size.

\section{Fishing trials and fishing area}

A total of 38 fishing trials were carried out between 1999 and 2001 during the first semester (which includes the peak season for this fishery), on board the R/V Donax, at depths ranging from 150 to $300 \mathrm{~m}$ (Fig. 1), off the south coast of the Algarve. The adopted soak time was that used by the commercial fishermen, corresponding to setting the nets in the afternoon and retrieving them the following morning.

\section{Data collection}

A total of 2858 hake specimens were caught. The fishes were sorted by mesh size, sexed, weighed

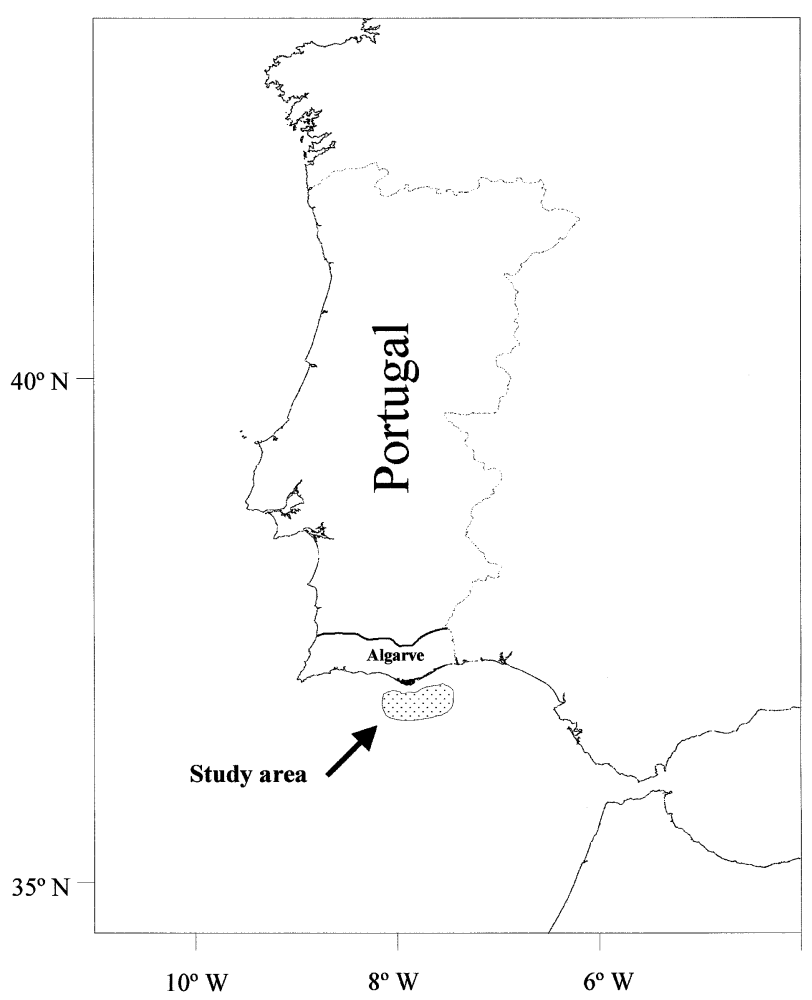

Fig. 1 Geographical location of the Algarve coast (southern Portugal), with particular emphasis on the study area (dotted area).

Table 1 Technical parameters for the experimental gill nets

\begin{tabular}{lcccc}
\hline Nominal mesh size $(\mathrm{mm})$ & 70 & 80 & 90 & 100 \\
\hline Measured mesh size (mm) $( \pm \mathrm{SD})$ & $69.5 \pm 0.5$ & $81.0 \pm 0.5$ & $88.5 \pm 0.6$ & 1098 \\
Net length (no. meshes) & 1380 & 1260 & 70.5 & $96.3 \pm 0.5$ \\
Net height (no. meshes) & 90.5 & 77.5 & 50.0 & 65.5 \\
Float line length (m) & 47.8 & 50.6 & 52.3 & 47.6 \\
Lead line (m) & 49.9 & 52.9 & 49.5 \\
\hline
\end{tabular}


and the TL was measured to the nearest lower centimeter. Each fish was classified according to different means of capture: ${ }^{16}$ (i) wedged: fish held tightly by a mesh around the body (includes snagged fish, i.e. meshed around the head region); (ii) gilled: fish prevented from backing out of the net, by a mesh caught behind the gill cover; or (iii) entangled: fish held in the net by teeth, maxillaries, or other projections, without necessarily penetrating the mesh.

\section{Estimation of gill net selectivity}

The gill net selectivity was estimated by means of the GILLNET $^{\odot}$ Software (ConStat, Hjoerring, Denmark) that is based on the 'share each length class catch total' (SELECT) method. ${ }^{23}$ This is a general statistical model that estimates gill net selection curves (i.e. retention probabilities) from comparative gill net catch data. In this method the expected catch proportions are fitted to the observed catch proportions using maximum likelihood, under the assumption that catches are Poisson random variables. ${ }^{24}$ The general SELECT model ${ }^{20}$ for analyzing data from comparative fishing trials with gears of different dimensions is described by the following expression:

$$
n_{l j} \approx \operatorname{Pois}\left(p_{j} \lambda_{l} r_{j}(l)\right)
$$

The log-likelihood of $n_{l j}$ is:

$$
\sum_{l} \sum_{j}\left\{n_{l} \log _{e}\left[p_{j} \lambda_{l} r_{j}(l)\right]-p_{j} \lambda_{l} r_{j}(l)\right\}
$$

where $n_{l j}$, the number of fish of length $l$ caught in mesh size $j$, has a Poisson distribution with mean $p_{j}(l) \lambda_{l} r_{j}(l): \mathrm{n}_{l} \approx \operatorname{Pois}\left(p_{j}(l) \lambda_{l} r_{j}(l)\right) ; \lambda_{l}$ is the abundance of length $l$ fish contacting the combined gear; $p_{j}(l)$ is the relative fishing intensity, which is the probability that a fish of length $l$ contacts gear $j$, given that it has come into contact with the combined gear. The number of length $l$ fish contacting gear $j$ is Poisson distributed with mean $p_{j}(l) \lambda_{i} ; r_{j}(l)$ is the contact selection curve for given gear size $j .{ }^{20}$

The number of estimated parameters is reduced in the SELECT method because proportions of the total catch for each length class and each gear are used $\left(y_{l j}=n_{l j} / n_{L+}\right.$, where $n_{l+}$ is the total catch for each length class for all gears), thereby eliminating the $\lambda_{l}$ parameters (abundance) as a nuisance parameter. The proportions have a multinomial distribution with $n_{l_{+}}$trials and probabilities:

$$
\phi_{l j}=\frac{p_{j} r_{j}(l)}{\sum_{j} p_{j} r_{j}(l)}
$$

where $j=1$ to $J$ (for $J$ mesh sizes).

The log-likelihood for the proportions $\left(\mathrm{y}_{l j}\right)$ is:

$$
\sum_{l} \sum_{j} n_{l j} \log _{e}\left(\phi_{l j}\right)
$$

Six different models (normal scale; normal location; gamma; log-normal; gamma semi-Wileman; and binormal) were tested in the present study. The equations are shown here.

Normal location:

$$
\exp \left(-\frac{(l-k \cdot m)^{2}}{2 \sigma^{2}}\right)
$$

Normal scale:

$$
\exp \left(-\frac{\left(l-k_{1} \cdot m_{j}\right)^{2}}{2 k_{2}^{2} \cdot m_{j}^{2}}\right)
$$

Log-normal:

$$
\frac{m_{j}}{l . m_{1}} \exp \left(\mu-\frac{\sigma^{2}}{2}-\frac{\left(\log (l)-\mu-\log \left(\frac{m_{j}}{m_{1}}\right)\right)^{2}}{2 \sigma^{2}}\right)
$$

Gamma:

$$
\left(\frac{l}{(\alpha-1) \cdot k \cdot m_{j}}\right)^{\alpha-1} \exp \left(\alpha-1-\frac{l}{k \cdot m_{j}}\right)
$$

Gamma semi-Wileman

$=$ gamma $(l, m ; k, \alpha)$ for $l<k(\alpha-1) m$; = (gamma $(l, m ; k, \alpha)+(c) /(1+c)$ for $l \geq k(\alpha-1) m$ (9)

Binormal:

$$
\exp \left(-\frac{\left(l-k_{1} \cdot m_{j}\right)^{2}}{2 k_{2}^{2} \cdot m_{j}^{2}}\right)+c \cdot \exp \left(-\frac{\left(l-k_{3} \cdot m_{j}\right)^{2}}{2 k_{4}^{2} \cdot m_{j}^{2}}\right)
$$

where $l$ is the total length $(\mathrm{cm}), m_{l}$ is the smallest mesh size $(70 \mathrm{~mm})$ and $\mathrm{m}_{j}$ is mesh size $j$.

For each model the data were fitted under both the assumptions of equal effort and effort proportional to mesh size. The latter case implies that the relative fishing intensity, $p_{j}$ is assumed to be proportional to mesh size because effort is proportional to mesh size. Goodness of fit was evaluated by comparison of deviances and examination of the deviance residuals plots, with the lowest deviance value corresponding to the best fitting model. ${ }^{20}$ Further details of the SELECT and 
GILLNET methods are provided in a number of publications. ${ }^{19,20,25,26}$

\section{Data analysis}

The Kolmogorov-Smirnov (K-S) test was used to compare the catch size frequency distributions and the Mann-Whitney (M-W) rank-sum test was applied to compare the mean sizes, with a $95 \%$ confidence interval. Fishing yields from different mesh sizes were compared by means of the Wilcoxon's matched pair test. ${ }^{27}$

\section{RESULTS}

\section{Catch distributions, sex ratios and fishing yields}

Hake were caught in the same size range from 17 to $65 \mathrm{~cm}$ TL by all mesh sizes (Fig. 2). The K-S test showed significant differences between all catch size frequency distributions except for those of the two largest mesh sizes (Table 2). The mean TL were $39.7,43.6,45.4$ and $45.0 \mathrm{~cm}$ for the $70,80,90$ and $100 \mathrm{~mm}$ nominal mesh sizes, respectively (Table 3 ). The comparisons of mean size between all mesh sizes showed significant differences, except in the case of the comparison between the 90 and $100 \mathrm{~mm}$ nominal meshes (Table 4). The modal classes corresponding to the four catch size distributions were $38.0-39.9 \mathrm{~cm}, 44.0-45.9 \mathrm{~cm}, 48.0-$ $49.9 \mathrm{~cm}$ and $46.0-47.9 \mathrm{~cm}$, for the $70,80,90$ and $100 \mathrm{~mm}$ nominal mesh sizes, respectively. The percentage of undersized fishes $(<27 \mathrm{~cm} \mathrm{TL})$ caught by the different nets varied between $0.6 \%$ and $2.1 \%$, increasing with mesh size.

Male fish dominated the catches in the smaller size classes up to approximately $41 \mathrm{~cm}$ length. On the contrary, female fish predomi- nated over male fish in the larger size classes, with no male fish found among fish of $\geq 56 \mathrm{~cm}$ length (Fig. 3).
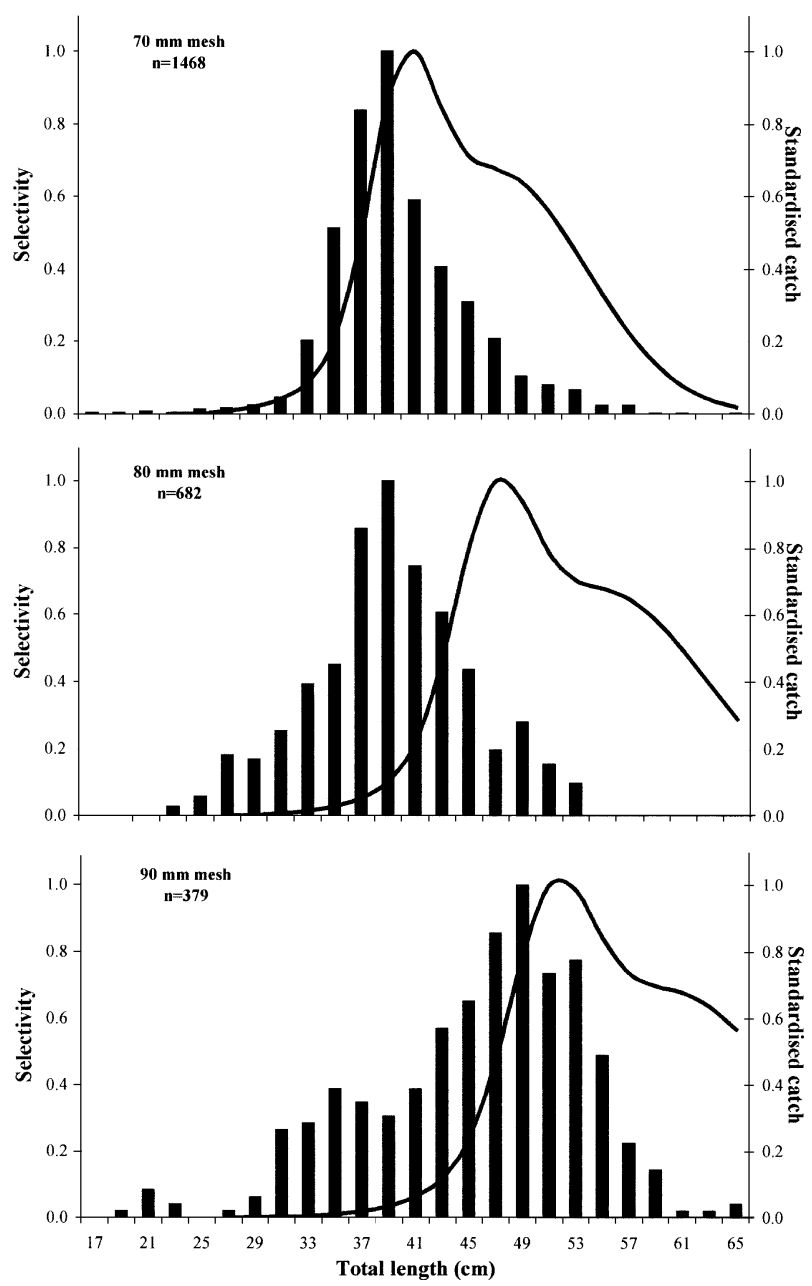

Fig. 2 Observed catch size frequency for hake and the fitted binormal selectivity curves for wedged and gilled fish for the 70, 80 and $90 \mathrm{~mm}$ gill net mesh sizes.

Table 2 Results of the Kolmogorov-Smirnov test used to compare the catch size frequency distributions for Merluccius merluccius

\begin{tabular}{lccccc}
\hline Mesh size $(\mathrm{mm})$ & $\mathrm{m}$ & $\mathrm{n}$ & $\mathrm{D}_{\max }$ & Critical value of $\mathrm{D}_{\mathrm{m}, \mathrm{n}}$ & \\
\hline 70 vs 80 & 1468 & 682 & 0.349 & 0.063 & $\mathbf{H}_{\text {o }}$ rejected \\
70 vs 90 & 1468 & 379 & 0.457 & 0.078 & $\mathbf{H}_{\mathbf{o}}$ rejected \\
70 vs 100 & 1468 & 329 & 0.417 & 0.083 & $\mathbf{H}_{\mathbf{o}}$ rejected \\
80 vs 90 & 682 & 379 & 0.195 & 0.087 & $\mathbf{H}_{\text {o }}$ rejected \\
80 vs 100 & 682 & 329 & 0.174 & 0.102 & $\mathbf{H}_{\mathbf{o}}$ rejected \\
90 vs 100 & 379 & 329 & 0.083 & 0.087 & $\mathbf{H}_{\mathbf{o}}$ not rejected \\
$70 \mathrm{~W}$ vs $70 \mathrm{E}$ & 896 & 572 & 0.045 & 0.128 & $\mathbf{H}_{\mathbf{o}}$ not rejected \\
$80 \mathrm{~W}$ vs $80 \mathrm{E}$ & 420 & 262 & 0.305 & 0.174 & $\mathbf{H}_{\text {o }}$ rejected \\
$90 \mathrm{~W}$ vs $90 \mathrm{E}$ & 242 & 137 & 0.300 & 0.182 & $\mathbf{H}_{\mathbf{o}}$ rejected \\
$100 \mathrm{~W}$ vs $100 \mathrm{E}$ & 188 & 141 & 0.429 & & $\mathbf{H}_{\mathbf{o}}$ rejected
\end{tabular}

W, wedged or gilled; E, entangled. 


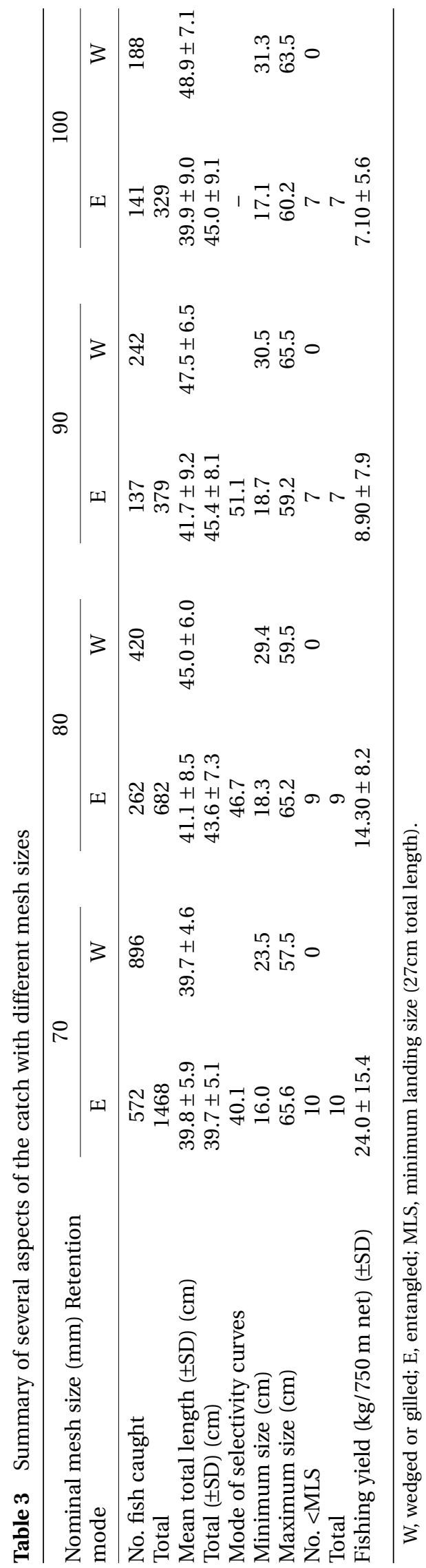

Table 4 Results of the Wilcoxon's matched pair test used to compare the fishing yields for Merluccius merluccius between mesh sizes

\begin{tabular}{lcrcc}
\hline Mesh size $(\mathrm{mm})$ & $\mathrm{N}$ & \multicolumn{1}{c}{$\mathrm{T}$} & $\mathrm{Z}$ & $P$ \\
\hline 70 vs 80 & 38 & 99 & 3.937 & $<\mathbf{0 . 0 0 0 1}$ \\
70 vs 90 & 38 & 31 & 4.924 & $\mathbf{< 0 . 0 0 0 1}$ \\
70 vs 100 & 38 & 1 & 5.359 & $<\mathbf{0 . 0 0 0 1}$ \\
80 vs 90 & 38 & 86 & 4.126 & $<\mathbf{0 . 0 0 0 1}$ \\
80 vs 100 & 38 & 30 & 4.938 & $\mathbf{< . 0 0 0 1}$ \\
90 vs 100 & 38 & 280 & 1.313 & 0.1894 \\
\hline
\end{tabular}

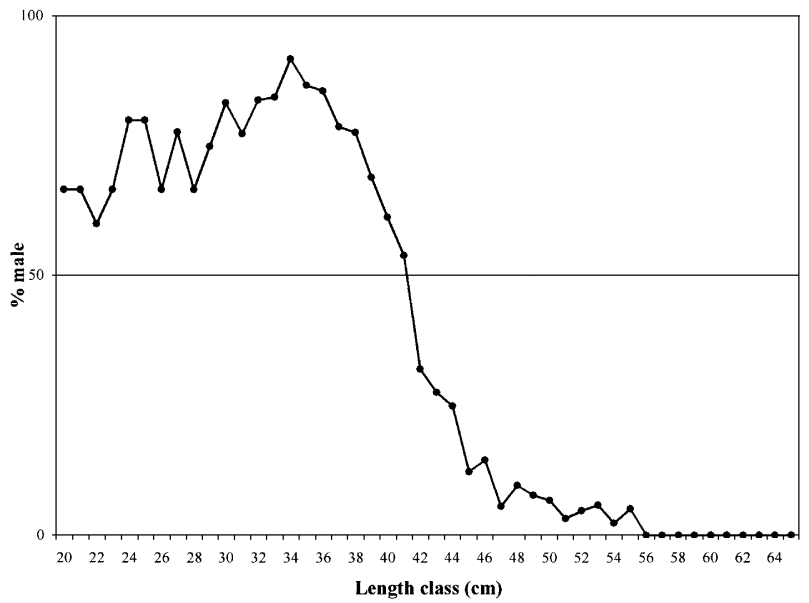

Fig. 3 Sex ratio (male:female) for the combined catches with the 70, 80, 90 and $100 \mathrm{~mm}$ gill nets.

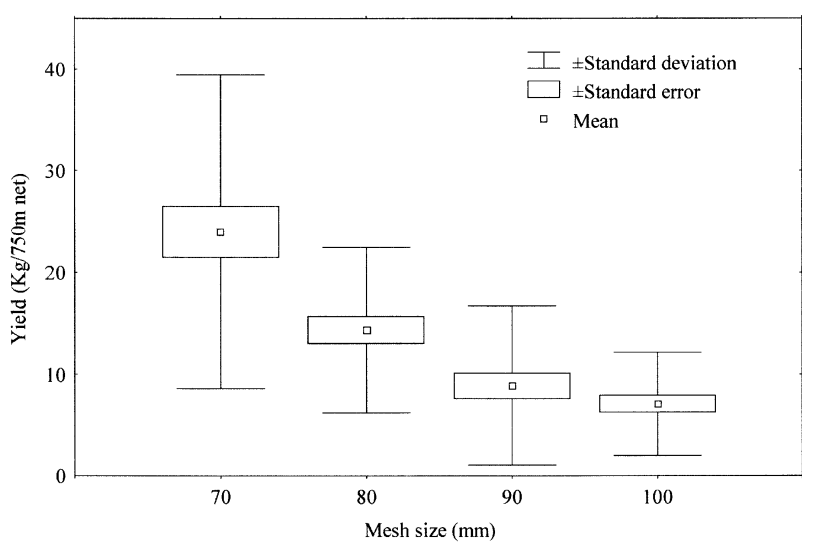

Fig. 4 Hake mean fishing yields by mesh size $(\mathrm{kg} / 750 \mathrm{~m}$ net). 
The fishing yield decreased dramatically with an increase in mesh size, ranging from $24.0 \mathrm{~kg} / 750 \mathrm{~m}$ of netting for the $70 \mathrm{~mm}$ mesh size to $7.1 \mathrm{~kg} / 750 \mathrm{~m}$ of netting for the $100 \mathrm{~mm}$ mesh size (Table 2; Fig. 4). The results of the Wilcoxon's matched pairs test (Table 4) showed significant differences between all mesh sizes, except for $90 \mathrm{~mm}$ versus $100 \mathrm{~mm}$ meshes.

\section{Method of capture}

Most specimens (between $57.1 \%$ and $63.9 \%$ ) were observed to have meshes stretched tight diagonally across the body (wedged or gilled), between the head and the region of maximum girth. Among these approximately one-third had a mesh caught behind the gill cover (gilled). The proportion of entangled fish was relatively constant for the four mesh sizes, ranging from $36.1 \%$ to $42.9 \%$ (Table 3 ). All specimens under the minimum legal size $(27 \mathrm{~cm} \mathrm{TL})$ were caught by entanglement. For the three largest mesh sizes there were highly significant differences (K-S test: $P<0.001$ ) between the catch size frequency distributions of hake that were tangled and those that were wedged (Table 2). However, when all methods of capture were considered, significant differences (K-S test: $P<0.001$ ) between all mesh sizes were found, with the exception of the two larger meshes (Table 2).

An increase in the mean size with mesh size was observed for wedged fish $(39.7-48.9 \mathrm{~cm})$ while mean sizes of entangled fish varied from 39.8 to $41.7 \mathrm{~cm}$, with no clear relationship with mesh size (Table 3). With the exception of the $70 \mathrm{~mm}$ mesh size, there were highly significant differences $(\mathrm{M}-\mathrm{W}$ test: $P<0.001)$ between the mean sizes of wedged and entangled hake for all mesh sizes. However, when all methods of capture were considered, significant differences in mean sizes were found

Table 5 Results of the Mann-Whitney rank-sum test used to compare the mean size for Merluccius merluccius

\begin{tabular}{lcccr}
\hline Mesh size $(\mathrm{mm})$ & $\mathrm{n}$ & $\mathrm{m}$ & $\mathrm{T}$ & \multicolumn{1}{c}{$P$} \\
\hline 70 vs 80 & 1468 & 682 & 914912 & $<\mathbf{0 . 0 0 1}$ \\
70 vs 90 & 1468 & 379 & 480820 & $<\mathbf{0 . 0 0 1}$ \\
70 vs 100 & 1468 & 329 & 388602 & $<\mathbf{0 . 0 0 1}$ \\
80 vs 90 & 682 & 379 & 224775 & $<\mathbf{0 . 0 0 1}$ \\
80 vs 100 & 682 & 329 & 181342 & $<\mathbf{0 . 0 0 1}$ \\
90 vs 100 & 379 & 329 & 116001 & 0.817 \\
70 E vs $70 \mathrm{~W}$ & 572 & 896 & 414836 & 0.564 \\
80E vs $80 \mathrm{~W}$ & 262 & 420 & 71797 & $<\mathbf{0 . 0 0 1}$ \\
90E vs 90W & 137 & 242 & 19795 & $<\mathbf{0 . 0 0 1}$ \\
100E vs 100W & 141 & 188 & 15847 & $<\mathbf{0 . 0 0 1}$
\end{tabular}

W, wedged or gilled; E, entangled. between all mesh sizes, with the exception of the two larger meshes (Table 5).

\section{Gill net selectivity}

The results of the SELECT model fits for all models are given in Table 6 . Because of the high degree of overlap between the catch size frequency distributions of the two largest mesh sizes, the models were fitted using only data for the 70,80 and $90 \mathrm{~mm}$ nominal mesh sizes. Due to the considerable dispersion resulting from the wide range of sizes caught by each mesh size, entangled fish were not considered in the analysis.

As shown in Table 6, the binormal model with effort proportional to mesh size gave the best fit, as indicated by the low deviance value that is of a similar order of magnitude as the degree of freedom and by the $P$ values $(P>0.05)$.

The observed catch size frequency distributions of wedged hake and the fitted binormal selectivity curves are shown in Fig. 2. The estimated modal lengths and spreads for the three mesh sizes were $\quad 40.09 \pm 2.42 \mathrm{~cm}, \quad 46.72 \pm 2.82 \mathrm{~cm}$ and $51.05 \pm 3.08 \mathrm{~cm}$, where the spread is the statistic of the selectivity curve that corresponds to the standard deviation of the density curve from which it is scaled (Holst R, pers. comm., 2002). While the catch distributions are to a great extent uni-modal, there are small secondary modes that justify the use of a binormal selectivity model. The main modal lengths of the fitted selectivity curves increase with mesh size, with smaller, less pronounced peaks in the selectivity curves at larger sizes (Fig. 2). The deviance residuals of the binormal model fits are shown in Fig. 5 and indicate that the fit is satisfactory.

\section{DISCUSSION}

One of the priorities of the Fisheries Common Policy of the European Commission is the promotion of selective fishing gears. Gill nets are highly size-selective gears that generally catch a relatively narrow size range consisting of few or no fish with lengths $20 \%$ less than or $20 \%$ greater than the optimum length of a particular mesh size. ${ }^{16,28}$ The widespread use of minimum mesh sizes in fisheries management has meant that gill net selectivity has received considerable attention, with numerous studies worldwide. ${ }^{16,29-33}$

The present study is one of the few concerning gill net selectivity for the European hake. Hake were caught in the same wide size range by all four mesh sizes used in the fishing trials. This is due in large part to the fact that, while most hake were wedged (held tightly by a mesh around the body or 


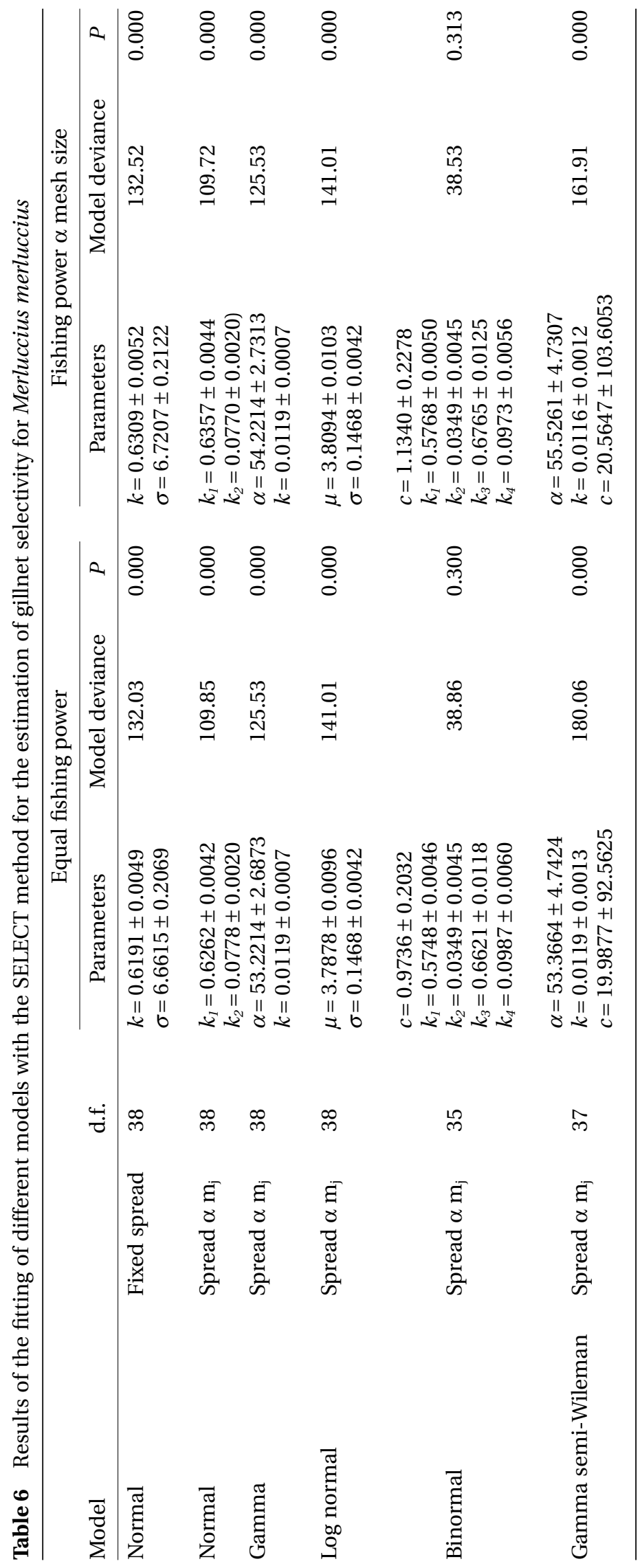




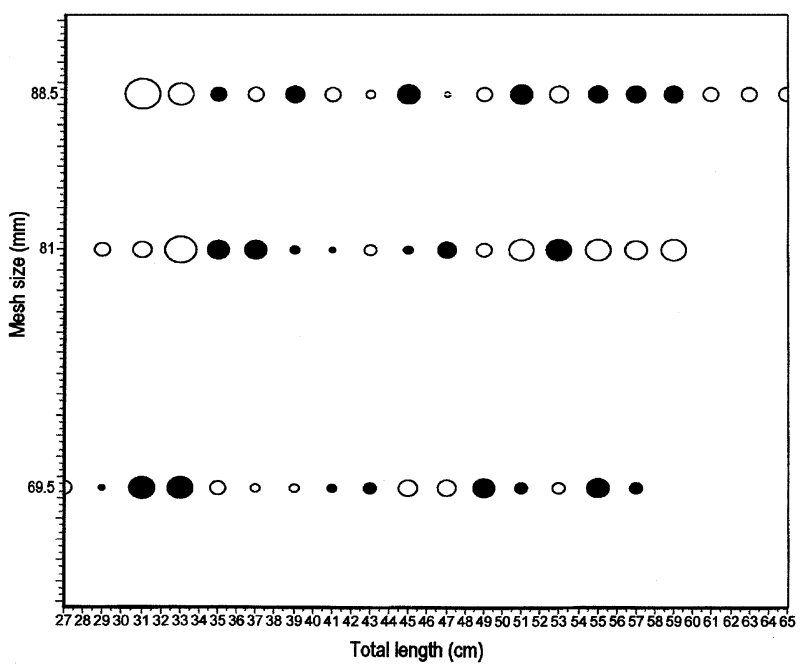

Fig. 5 Deviance residual plot corresponding to the binormal model fits.

gilled), significant proportions of the catches within each mesh size were entangled. Nevertheless, the catch size distributions clearly showed that there was size selectivity, with an increase in mean size with greater mesh size.

When a species is caught mainly by wedging or by being gilled, the estimated selectivity curves are bell-shaped. This was not the case for hake in the present study where, as aforementioned, wedging, gilling and entangling were all significant. Thus, as a first approach it was not possible to fit any selectivity model to the observed catch size frequency distributions. However, when the entangled fish were removed, good fits were obtained for the binormal model as can be seen in the plots of the deviance residuals.

In the present study, relative fishing intensity was assumed to be either fixed or proportional to mesh size. However, Fujimori and Tokai showed how $p_{j}$ can be estimated, with significant improvement in the fits obtained. ${ }^{34}$ In their analysis of pink salmon, Oncorhynchus gorbushia, data for six mesh sizes, the binormal model with $p_{j}$ estimated was the best model, with an improvement in the fitting compared to fixed $p_{j}$ or $p_{j}$ proportional to mesh size.

It should be noted that hake smaller than those that are wedged or gilled are entangled. From the management perspective this is a problem that cannot be resolved by a minimum mesh size regulation because even quite small fish can get entangled by the teeth in very large mesh sizes. Thus, we focus on the selectivity of wedging, which accounts for the majority of the hake caught in gill nets.

The estimated curve for the $70 \mathrm{~mm}$ nominal mesh overlaps the observed catch size frequency distribution. However, with increasing mesh size there is a shift to the right of the fitted selectivity curves in relation to the corresponding catch distributions. Thus, for the larger mesh sizes, the modal lengths of the selectivity curves based on the SELECT model are generally greater than those of the observed catch size frequency distributions. The modes of the estimated selectivity curves were $1.1,1.7$ and $2.0 \mathrm{~cm}$ greater than those of the length frequency distributions of the catch, for the 70,80 and $90 \mathrm{~mm}$ nominal mesh sizes, respectively. This is probably due to the fact that the Baranov principle of geometric similarity (i.e. that modal lengths are proportional to mesh size) is observed for all but one of the models fitted using the SELECT method in the GILLNET software. This may also contribute to greater modal lengths than expected, especially in the case of overlapped catch distributions.

The demographic structure of hake populations is strongly depth-related, with juveniles found on the continental shelf and the largest adults on the upper continental slope. ${ }^{35}$ With deep water as a partial refuge for the spawning stock, the hake has been able to persist despite heavy fishing pressure and high mortality of undersized individuals caught as by-catch and discarded in trawl fisheries. In the Algarve coast, the deepwater hake gill net fishery is a recent development, which has significantly increased the effort and largely replaced the traditional semipelagic long-line fishery for large hake. ${ }^{36}$

The present study has shown that hake are caught in the same size range by all mesh sizes (between 17 and $65 \mathrm{~cm} \mathrm{TL}$ ), with the majority of the catch of all mesh sizes consisting of female fish. However, in contrast with the three larger mesh sizes, the mode of the fitted selectivity curve of the $70 \mathrm{~mm}$ gill net is greater than the estimated size at maturity $\left(\mathrm{L}_{50}=45.3 \mathrm{~cm}\right.$ TL) for hake in Portuguese waters. ${ }^{37}$ Given the fact that the $70 \mathrm{~mm}$ mesh size gill net is significantly more effective in terms of catch per unit effort than the larger mesh sizes tested in the present study and that there is considerable discarding of damaged or scavenged hake, ${ }^{14}$ it would therefore be advisable to increase the minimum mesh size to at least $80 \mathrm{~mm}$. This precautionary measure would ensure that a large part of the catch would consist of hake larger than the estimated size at maturity and would contribute to the goals of conservation and sustainability of this fishing resource.

\section{ACKNOWLEDGMENTS}

We thank the staff of Instituto de Investigação das Pescas e do Mar, Centro Regional de Investigação 
Pesqueira do Sul (E Brás, R Machado, L Oliveira, T Simões and JL Sofia) for collecting data and the crew of R/V Donax for their skillful handling of the fishing gears and the catches. We also thank R Sá for help during the initial stages of the present study and P Vasconcelos and R Coelho for their assistance with the preparation of this manuscript. The authors would like to acknowledge the European Commission (EC) for partially supporting this study (DG XIV Study Contract no. 97/ 0064). The present article does not necessarily reflect the views and in no way anticipates any future opinion of the EC.

\section{REFERENCES}

1. Casey J, Pereiro J. European hake (M. merluccius) in the North-east Atlantic. In: Alheit J, Pitcher TJ (eds). Hake: Biology, Fisheries and Markets. Fish and Fisheries Series no. 15. Chapman \& Hall, London. 1995; 125-147.

2. Moreira CD. Populações Marítimas em Portugal. Universidade Técnica de Lisboa, Lisboa. 1987.

3. Sanches JG. Guia para identificação do pescado de Portugal submetido a tamanho mínimo de captura. Publicações Avulsas do INIP, no. 18, Lisboa. 1992.

4. Aldebert Y, Carries C. Problèmes d'exploitation du merlu dans le Golfe du Lion. FAO Rapp. Pêches 1988; 395: 87-91.

5. Martin P. La pesca en Cataluña y Valencia (NO Mediterráneo). Análisis de las series históricas de captura y esfuerzo. Inf. Téc. Sci. Mar. 1991; 162: 1-43.

6. Oliver PA, Massuti E. Biology and fisheries of western Mediterranean hake (M. merluccius). In: Alheit, J Pitcher TJ (eds). Hake: Biology, Fisheries and Markets. Fish and Fisheries Series no. 15. Chapman \& Hall, London. 1995; 181-202.

7. Food and Agriculture Organization. Review of the state of world fishery resources: Marine fisheries. 2: Northeast Atlantic (FAO Statistical Area 27). FIRM/C920. FAO Fish. Circ. 1997; 920: 10

8. Cardénas E, Villamor B, Pereda P. Description of the Spanish long-liner fishery in division VIIIa,b. 1987/G. ICES Council Meeting 1987; session G paper 21: 14.

9. Aldebert Y, Recasens L, Lleonart J. Analysis of gear interactions in a hake fishery. The case of the Gulf of Lions (NW Mediterranean). Sci. Mar. 1993; 57: 207-217.

10. Brabant JC, Fontaine B, George JP, Jacqueline F, Mortreux S, Sacchi J. Selectivity of Gillnets in the North Sea, English Channel and Bay of Biscay. Periodic Report EU AIR2 Project CT93/1122. Centre de Bologne sur Mer, Bologne sur Mer, France. 1994.

11. Martos AR, Peralta LF. Biology and fisheries of Northwest African hakes (M. merluccius, M. senegalensis and M. polli). In: Alheit J, Pitcher TJ (eds). Hake: Biology, Fisheries and Markets. Fish and Fisheries Series no. 15. Chapman \& Hall, London. 1995; 89-124.

12. Papaconstantinou C, Stergiou KI. Biology and fisheries of eastern Mediterranean hake (M. merluccius). In: Alheit J, Pitcher TJ (eds). Hake: Biology, Fisheries and Markets. Fish and Fisheries Series no. 15. Chapman \& Hall, London. 1995; $149-180$.
13. Anonymous. Selectivité des filets cales en Mediterranée. Rapport final EU Project 95/C/76/12: SELMED. IFREMER CETEMAR, ICRAM, NCMR, Sète, France. 1998.

14. Santos MN, Gaspar MB, Monteiro CC, Vasconcelos P. Gill net and long-line comparisons in a hake fishery: the case of southern Portugal. Sci. Mar. 2002; 66: 433-441.

15. DGPA. Datapescas - Difusão, no. 46. Ministério da Agricultura Desenvolvimento Rural e Pescas, Lisboa. 2000.

16. Hamley JM. Review of gillnet selectivity. J. Fish. Res. Board Can. 1975; 32: 1943-1969.

17. Holst R, Moth-Poulsen T. Numerical recipes and statistical methods for gillnet selectivity. 1995/B. ICES Council Meeting 1995; session G paper 21: 18.

18. Hovgård H. A two-step approach to estimating selectivity and fishing power of research gill nets used in Greenland waters. Can. J. Fish. Aquat. Sci. 1996; 53: 1007-1013.

19. Millar RB, Holst R. Estimation of gill net and hook selectivity using log-linear models. ICES J. Mar. Sci. 1997; 54: 471-477.

20. Millar RB, Fryer RJ. Estimating the size-selection curves of towed gears, traps, nets and hooks. Rev. Fish Biol. Fish. 1999; 9: 1-28.

21. Dunlin GR. Selectivity of gillnets in the North Sea, English Channel and Bay of Biscay. Consultancy Report no. 116. Sea Fish Industry Authority: Technology Division, Hull, UK. 1996.

22. Sá RSB. Contribuição para o estudo da selectividade das redes de emalhar de um pano fundeadas para a pescada (Merluccius merluccius, Linnaeus, 1758). Thesis of the Marine Biology and Fisheries Degree, University of the Algarve, Faro, 1999.

23. ConStat. gillnet ${ }^{\odot}$ Software. ConStat, Denmark. 1998.

24. Millar RB. The functional form of hook and gill net selection curves cannot be determined from comparative catch data alone. Can. J. Fish. Aquat. Sci. 1995; 52: 883-891.

25. Huse I, Nedreaas K. Preliminary length selection curves for trawl fishing for Greenland halibut (Reinhardtius hippoglossoides). 1995/22. NAFO SCRD 1995.

26. Boje J, Hoslt R, Woll A. Selectivity in longline fishery for Greenland halibut. ICES FTFB WG Meeting, 20-23 April 1998: La Coruña. Working Document. ICES, Copenhagen. 1998.

27. Snedecor GW, Cochran WG. Statistical Methods, 8th edn. State University Press, Iowa. 1989.

28. Hamley JM. Sampling with gill nets. In: Bachiel T, Welcomme RL (eds). Guidelines for Sampling Fish in Inland Waters. FAO, European Inland Fisheries. Advisory Commission Technical Paper no. 33. Food and Agriculture Organiztion, Rome. 1980; 37-53.

29. McCombie AM, Fry FEJ. Selectivity of gill nets for lake whitefish, Coregonus clupeaformis. Trans. Am. Fish. Soc. 1960; 89: 176-184.

30. Regier HA, Robson DS. Selectivity of gill nets, especially to lake whitefish. J. Fish. Res. Board Can. 1966; 23: 423454.

31. Hamley JM, Regier HA. Direct estimates of gillnet selectivity to walleye (Strizostedion vitreum vitreum). J. Fish. Res. Board Can. 1973; 30: 817-830.

32. Karunasinghe WPN, Wijeyaratne MJS. Selectivity estimates for Amblygaster sirm (Clupeidae) in the small-meshed gill net fishery on the west coast of Sri Lanka. Fish. Res. 1991; 10: 199-205.

33. Reis EG, Pawson MG. Determination of gill-net selectivity 
for bass (Dicentrarchus labrax L.) using commercial catch data. Fish. Res. 1992; 13: 173-187.

34. Fujimori Y, Tokai T. Estimation of gillnet selectivity curve by maximum likelihood method. Fish. Sci. 2001; 67: 644654.

35. Recasens L, Lombarte A, Morales-Nin B, Torres GJ. Spatiotemporal variation in the population structure of the European hake in the NW Mediterranean. J. Fish. Biol. 1998; 53: $387-401$.
36. Erzini K, Gonçalves JMS, Bentes L, Lino PG, Ribeiro J. The hake semi-pelagic ('pedra-bola') longline fishery in the Algarve (southern Portugal). Fish. Res. 2001; 51: 327336.

37. Cardador F, Morgado C, Lucio P, Piñero C, Sainza M, Santurtun M. New maturity ogive for the southern stock of hake (ICES divisions VIIIC+IXa). ICES SSDS WG Meeting, 110 September, 1999, Copenhagen. Working Document. ICES, Cophenhagen. 1999. 